\title{
Evaluation of muscle regeneration in aged animals after treatment with low-level laser therapy
}

\section{Avaliação da regeneração muscular em animais idosos após tratamento com laser de baixa intensidade}

\author{
Adriana Pertille', Aline B. Macedo², Cássio P. V. Oliveira²
}

\begin{abstract}
Background: The aging process and its associated morphophysiological changes trigger a reduction in the regenerative ability of the satellite cells, a reduction of vascular tissue and an increase in the production of fibroblasts, developing a cellular environment unfavorable for muscle regeneration. Objective: The aim of this study was to evaluate the effect of low-level laser therapy on the muscle regeneration of old experimental rat models after contusion. Method: A total of 25 old rats, 18 months old, were divided into three groups: control group (CT) without treatment; injury group (IN) with muscle contusion and without treatment and laser group (LA) with contusion and low-level laser therapy, $830 \mathrm{~nm}, 30 \mathrm{~mW}$ e $4 \mathrm{~J} / \mathrm{cm}^{2}$. The no invasive contusion was induced in the Tibialis Anterior muscle and the samples were collected after 7 and 21 treatment sessions. The muscle was evaluated by Light Microscopy and Immunoblotting. Results: After 21 days of treatment there was a significant reduction in the areas of inflammation/regeneration of the LA 21 group compared to IN 21 group. The cross-sectional area of the fibers in regeneration was not statistically different between the groups. Molecular analysis showed that the content of MyoD was statistically reduced in the IN 21 group compared to the CT group. The Myogenin content was increased in the IN 21 group compared to the CT group. Ultimately, the content of TGF- $\beta 1$ on the IN 21 group was higher when compared to the CT group. Conclusion: Considering the parameters used, the laser therapy demonstrated to be effective for muscle regeneration in old rats, however only through its anti-inflammatory effect.
\end{abstract}

Keywords: aging; regeneration; physical therapy; low-level laser therapy.

\section{Resumo}

Contextualização: O processo de envelhecimento e suas consequentes alterações morfofisiológicas desencadeiam redução da habilidade regenerativa das células satélites, redução da vascularização tecidual e aumento da produção de fibroblastos, desenvolvendo-se um ambiente celular desfavorável para a regeneração muscular. Objetivo: Avaliar o efeito do tratamento com laser de baixa intensidade sobre a regeneração muscular de modelos experimentais idosos após contusão. Método: Foram utilizados 25 ratos machos, com 18 meses de idade, divididos em três grupos: grupo controle (CT), sem intervenção; grupo lesão (LE), com contusão muscular e sem tratamento e grupo laser (LA), com contusão muscular e tratado com laser de baixa intensidade, $830 \mathrm{~nm}$, $30 \mathrm{~mW}$ e $4 \mathrm{~J} / \mathrm{cm}^{2}$. A contusão foi realizada no músculo tibial anterior, e as amostras coletadas após sete e 21 sessões de tratamento. 0 músculo foi designado às técnicas de Microscopia de Luz e Immunoblotting. Resultados: Após 21 dias de tratamento, houve redução significativa na área de inflamação/regeneração no grupo LA 21 comparado ao grupo LE 21. Na área de secção transversal das fibras em processo de regeneração, não houve diferença estatística entre os grupos LA e LE. A análise molecular evidenciou que o conteúdo de $M y o D$ apresentou redução significativa no grupo LE 21 em relação ao CT. O conteúdo de Miogenina exibiu aumento no LE 21 comparado ao CT e, por fim, o conteúdo de TGF- $\beta 1$ do grupo LE 21 aumentou em relação ao grupo CT. Conclusão: Para os parâmetros utilizados, o laser demonstrou eficácia na regeneração muscular em animais idosos somente por meio do seu efeito anti-inflamatório.

Palavras-chave: envelhecimento; regeneração; fisioterapia; terapia a laser de baixa intensidade.

Received: 02/03/2012 - Revised: 05/29/2012 - Accepted: 06/03/2012 


\section{Introduction $: \therefore$.}

The maintenance of skeletal muscle regenerative potential depends on the age of the individual ${ }^{1}$. Morphophysiological changes that occur in tissues as a result of aging cause a decline in the activation and proliferation of satellite cells, an imbalance in Notch and Wnt signaling pathways, slow activation of inflammatory cells, increased fibroblast production, decreased vascularization, a thickening of the basal lamina and a reduction in the level of IGF-I.

The high incidence of muscle injuries in the elderly has led to an increase in the number of studies related not only to the process of repair, but also to physical therapeutic resources ${ }^{6}$. The low-level laser stands out as it known to trigger the production of adenosine triphosphate (ATP) ${ }^{7}$, promote angiogenesis and boost the entry of quiescent satellite cells in the cell cycle ${ }^{8}$. These therapeutic effects are known to make muscle regeneration more efficient, reducing their time and improving their quality ${ }^{9,10}$.

The laser effects are not restricted to muscle regeneration. Oliveira et al. ${ }^{11}$, after the induction of bone defects in the tibia of rats, reported an increase in the area of newly formed bone tissue with the use of irradiation. In the process of tendon repair, Arruda et al. ${ }^{12}$ identified that laser therapy was capable of promoting a better degree of collagen fiber organization along the longitudinal axis. Furthermore, Silveira et al..$^{13}$ noted that the laser was capable of stimulating antioxidant activity and protecting cells against oxidative damage in the healing of cutaneous wounds.

Although well-grounded in literature, most studies that use low level laser as a resource, whether in humans or in experimental models, are performed on young individuals or adults. However, it is known that a muscle function loss can significantly affect the quality of life of the elderly, because a loss in function and its consequent loss in independence, can also lead to psychological and emotional problems ${ }^{10}$.

In the light of the increasing life expectancy of the population, it is essential that physical therapists are knowledgeable about the specificities of muscle regeneration in the elderly and the applicability and effectiveness of low-level laser therapy, as well as its respective dose. Considering the biological effects of the laser, it is hypothesized that its application favors tissue repair even when the aging process is an issue. Therefore, this study aims to evaluate the effects of treatment with low-level laser therapy on the muscle regeneration of aged experimental rat models after injury.
Method $: \because$.

25 male Wistar rats, aged 18 months and weighing $591.87 \pm 64.06 \mathrm{~g}$, were used. The animals were kept under a controlled room temperature, 12 hour light/dark cycle, with plentiful water and animal food. This study was approved by the Ethics in Research Committee on Animal Experimentation of the Universidade Federal de São Carlos (UFSCar), São Carlos, SP, Brazil (Opinion 012/2010).

The animals were randomly divided into three experimental groups $(\mathrm{n}=5)$ : the control group $(\mathrm{CT})$, where the rats remained in the bioterium without any intervention; the injury group (IN), where the rats were subjected to injury, and remained untreated, and the laser group (LA), where rats subjected to muscle injury and received low-level laser therapy. The LA and IN groups were subdivided in order to assess the phases of muscle regeneration and, for this reason, treatments were applied for 7 (LA 7) or 21 (LA 21) sessions, while the IN group, despite not having received treatment, was sacrificed in the corresponding periods (IN 7 and IN 21).

To perform the non-invasive injury, animals were anesthetized intramuscularly with a ketamine $(0.09 \mathrm{~mL} / 100 \mathrm{~g})$ and xylazine $(0.06 \mathrm{~mL} / 100 \mathrm{~g})$ mixture. After anesthesia and trichotomy, the animals were positioned in the equipment in lateral decubitus, with right foot facing up and in maximum ankle plantar flexion. Next, a load of $284 \mathrm{~g}$ was released from a height of $35 \mathrm{~cm}$ to the tibialis anterior muscle (TA), totaling three consecutive impacts distributed in the proximal-medium and medial region of the muscle $^{14}$. After the procedure, palpation and mobilization were performed on the right foot to confirm the absence of bone fracture.

\section{Treatment}

\section{Low-level laser therapy}

The animals in the LA 7 and LA 21 groups received low-level laser therapy with use of the IBRAMED ${ }^{\circledR} l a-$ serpulse class 3B appliance, aluminum gallium arsenide (AIGaAs) diode, $830 \mathrm{~nm}$ wavelength, continuous emission, $30 \mathrm{~mW}$ output power, $0.07 \mathrm{~cm}^{2}$ beam area and energy density of $4 \mathrm{~J} / \mathrm{cm}^{2}$. The therapy was applied using the point technique, distributed in two points, with one point being directly over the injury and the other on the distal third of the muscle, at a distance of $1 \mathrm{~cm}$. The laser was applied in each point for 16 seconds and a transparent polyvinyl chloride (PVC) film was used on the laser emitting pen ${ }^{15}$. 
The equipment was previously calibrated by a laser power meter (Laser Check Model, COHERENT).

The treatment began 24 hours after the injury and took place daily, at 24 hour intervals, frequency of five times per week and interval of two days, totaling 7 or 21 sessions, according to the group.

\section{Euthanasia}

In the euthanasia of the animals, a high dose of anesthetic was injected intraperitoneally, followed by cardiac perfusion with $60 \mathrm{~mL}$ of Phosphate Buffered Saline (PBS). Following this procedure, the right TA muscle was removed and divided into two equal parts, one to be used for histological analysis, and the other for the Immunoblotting technique.

\section{Histological analysis}

Samples were fixed on a wooden support with tragacanth gum, and were then frozen in isopentane at $-80{ }^{\circ} \mathrm{C}$ and liquid nitrogen at $-159^{\circ} \mathrm{C}$. In producing the slides, the muscles were sectioned transversally with a thickness of $8 \mu \mathrm{m}$, using cryostat (Microm-HS505E) and subsequently stained with hematoxylin and eosin (HE).

Using a light microscope (Olympus, Optical Co. Ltd, Tokyo, Japan) and Pro-Plus ${ }^{\circledR} 6.2$ Image software (Media Cybernetics), two random sections from each animal were analyzed quantitatively through 4X and 20X objective lens. In the analysis of the inflammation/regeneration area, we measured the area of muscle in the stages of inflammation and regeneration, characterized by intense inflammatory infiltrate and the presence of fibers in regeneration. Results were obtained by calculating the proportion of this area with the section of the entire muscle. Another analysis performed was the quantification of the cross-sectional area (CSA) of the fibers in order to verify their regeneration maturation. Muscle fibers that had a centralized nucleus were indicative of regeneration and were measured and compared to normal fibers. In this analysis, 400 fibers in regeneration and 200 normal fibers were measured in each muscle slice.

\section{Molecular analysis}

Through the Immunoblotting technique, the MyoD, Myogenin and TGF- $\beta 1$ in the experimental groups were quantified. The muscles were homogenized in a buffer solution containing phosphatase and protease inhibitors (1\% Triton, $100 \mathrm{mM}$ sodium pyrophosphate, $0.1 \mathrm{mg} / \mathrm{mL}$ aprotinin, $2 \mathrm{mM}$ PMSF and $10 \mathrm{mM} \mathrm{Na}_{3} \mathrm{PO}_{4}$ ). The extracts were centrifuged for 20 minutes at $4^{\circ} \mathrm{C}$ and the supernatant was treated with Laemmli buffer (10\% SDS, 50\% glycerol, 0.1\% Bromophenol blue, 100
$\mathrm{mM}$ Tris-HCl (pH 7.4). Next, 50 gm of protein were applied to a $12 \%$ SDS-polyacrylamide gel. The proteins were transferred from the gel to the nitrocellulose membrane, using a Bio-Rad electro-transfer equipment. Membranes were blocked for 1 hour, at room temperature, with $5 \%$ skimmed milk diluted in a basal solution (10 mM Trisma base, $150 \mathrm{mM} \mathrm{NaCl}$ and 0.02\% Tween-20). The membranes were incubated with primary antibodies at $4{ }^{\circ} \mathrm{C}$ overnight, washed with basal solution and incubated with secondary antibodies conjugated in perixodase for 2 hours at room temperature. To detect immunoreactive bands, the membranes were exposed to a chemiluminescence kit (Super Signal West Pico Chemiluminescente, Pierce) for 5 minutes. The homogeneous distribution of sample loading was verified by staining with Ponceau dye. The optical densitometry of the bands was quantified by use of the Image J Program (The National Institute of Health, USA).

The following primary antibodies were used: (1) MyoD (m-318), Polyclonal rabbit, Santa Cruz: sc-760, (2) TGF- $\beta 1$, Monoclonal mouse, Sigma-Aldrich, T7039; (3) Myogenin, Monoclonal mouse, Sigma M5815. The corresponding secondary antibodies were: (1) Goat anti-rabbit IgG-HRP, sc-2004 (Santa Cruz) and (2) Goat anti-mouse IgG-HRP, sc-2005 (Santa Cruz).

\section{Statistical analysis}

In the statistical analysis, we applied the Shapiro-Wilk test to verify sample normality. For normally distributed data, a one-way ANOVA test was used, followed by the Tukey test, with data being presented as mean and standard deviation. For data with non-standard distribution, we applied the KruskalWallis test and subsequently the Student-Newman-Keuls test. In this case, data are presented as median and first and third quartiles. The analyses were processed through BioEstat 5.0 and SPSS 13.0 software, considering a 5\% significance level.

\section{Results $: \because$}

\section{Histological analysis}

The histological analysis allowed us to view and quantify the area of the injury which, in turn, was restricted to the surface of the TA muscle, and was characterized by an intense inflammatory infiltrate, apart from fibers in regeneration. In the initial stage of regeneration, the muscle fibers had a small diameter, with sparse and strongly basophilic cytoplasm, and the nucleus was centered and increased as a result of the intense protein 
synthesis. With the advance in repair, they exhibited an apparent increase in cytoplasm/core proportion, nucleus size close to normal, lower CSA when compared to normal fibers, and a reduction of inflammatory infiltrate around them ${ }^{16-18}$ (Figure 1).

A comparison of the inflammation/regeneration area between the groups demonstrated that the LA 21 group exhibited a significant reduction when compared to the IN 21 group. This result shows that, in 7 treatment sessions, the laser was not effective in reducing the area of injury as there was no difference between the IN 7 and LA 7 groups. However, with an increase in the number of treatment sessions, the laser produced a significant anti-inflammatory effect in the muscular regeneration of aged rats. The intra-group analysis showed that the laser is effective because the LA 7 and 21 group sessions demonstrated a marked reduction in the area

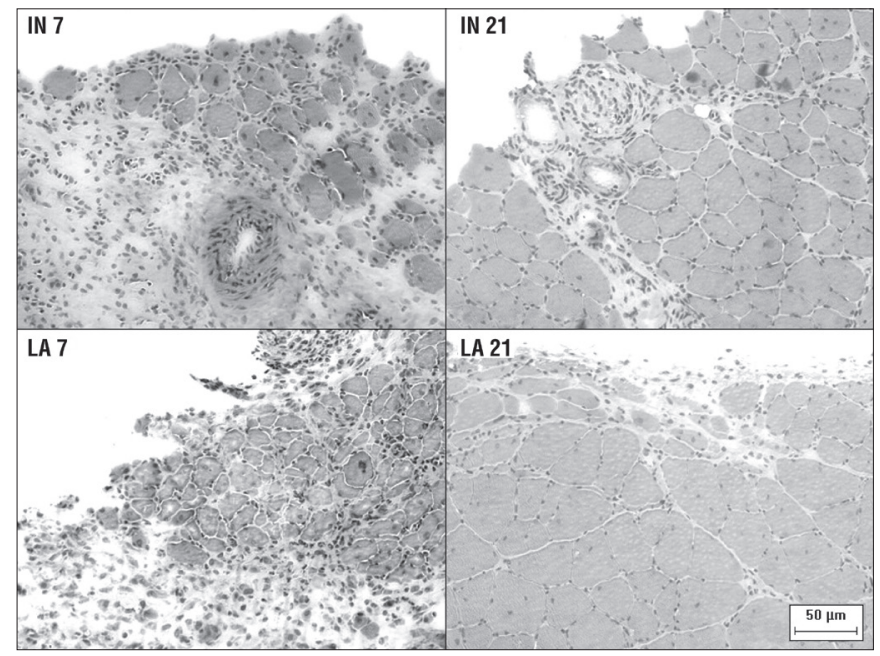

Figure 1. Muscle regeneration process in each group: injury 7 (IN 7), injury 21 (IN 21), laser 7 (LA 7) and laser 21 (LA 21).

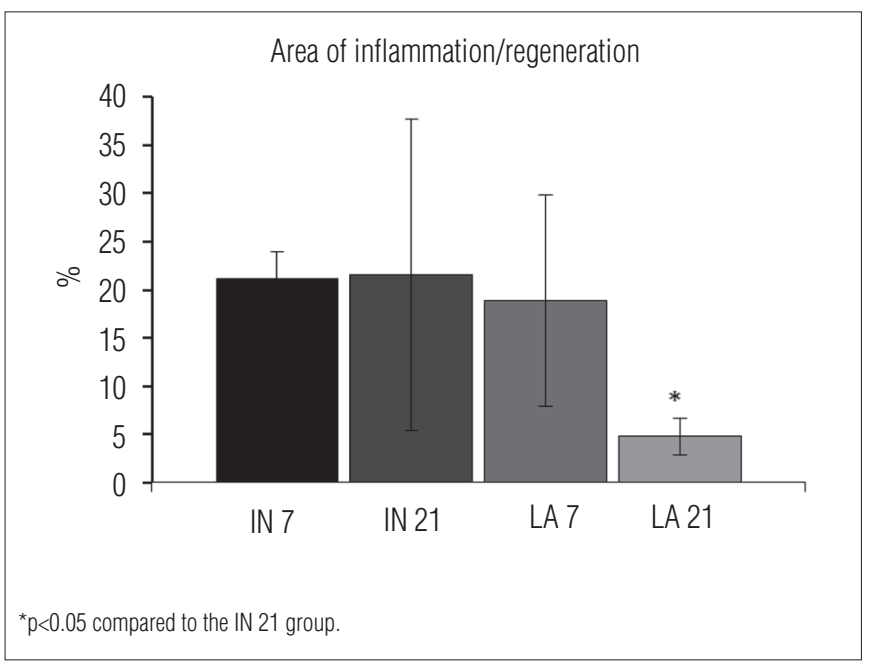

Figure 2. Area in process of inflammation/regeneration in each group: injury 7 (IN 7), injury 21 (IN 21), laser 7 (LA 7) and laser 21 (LA 21). (Mean \pm SD). of injury, emphasizing the advance in muscle regeneration after 21 treatment sessions (Figure 2).

The muscle fibers of the IN 7 and LA 7 groups had similar CSA and were significantly reduced compared to the fibers of the CT group, indicating that the cells of these groups were in the initial phase of regeneration and did not reach normal values. After 21 treatment sessions, despite the fact that the CSA of the muscle fibers had values close to normal, there were no statistical difference between the treated group in relation to the injured non treated group. The intra-group comparison showed a difference in the CSA of muscle fibers in the LA 7 and 21 groups, suggesting the maturation of muscle fibers over time. However, for the parameters used in this study, the laser was not capable of accelerating the maturation of the muscle fibers of aged rats, suggesting that regeneration occurred spontaneously and was not accelerated by treatment (Table 1).

\section{Molecular analysis}

One marker particular to the satellite cell activation and proliferation phase is the $\mathrm{MyoD}$ expression. The findings demonstrate that the IN 21 group had reduced MyoD content in relation to the $\mathrm{CT}$ group. Considering that none of the experimental groups showed elevated MyoD content compared to the CT group, it suggests that the satellite cell activation and proliferation phase had already occurred in the studied periods - thus, the MyoD content had already returned to normal (Figure 3).

The, Myogenin a characteristic marker of the satellite cell differentiation phase in muscle fibers during the regeneration process, was similar in the CT, IN 7 and LA 7 groups. So, at this first instance, regeneration seems to have occurred spontaneously, with no contribution from treatment. analysis performed in the latter phase of regeneration exhibited a significant increase of Myogenin content in the IN 21 group in relation to the CT group, while the LA 21 group showed similar content to the CT group. These results may suggest delayed

Table 1. Cross sectional area of the muscle fibers in regeneration. (Median \pm Q1-Q3).

\begin{tabular}{lcc}
\hline \multirow{2}{*}{ Group } & \multicolumn{2}{c}{ Area of fibers with peripheral nuclei $\left(\mu \mathrm{m}^{2}\right)$} \\
\cline { 2 - 3 } Control & \multicolumn{1}{c}{ Median } & Q1-Q3 \\
\hline & 2913.39 & $2462.95-2920.24$ \\
\hline Injury 7 & Area of central nucleated fibers $\left(\mu \mathrm{m}^{2}\right)$ \\
\hline Injury 21 & $836.78^{*}$ & $836.78-870.37$ \\
\hline Laser 7 & 1424.28 & $1424.28-1668.98$ \\
\hline Laser 21 & $1066.87^{\star \dagger}$ & $820.79-1270.73$ \\
\hline
\end{tabular}

${ }^{*} \mathrm{p}<0.05$ compared to the CT group; ${ }^{\mathrm{p}} \mathrm{p}<0.05$ compared to the LA 21 group. 

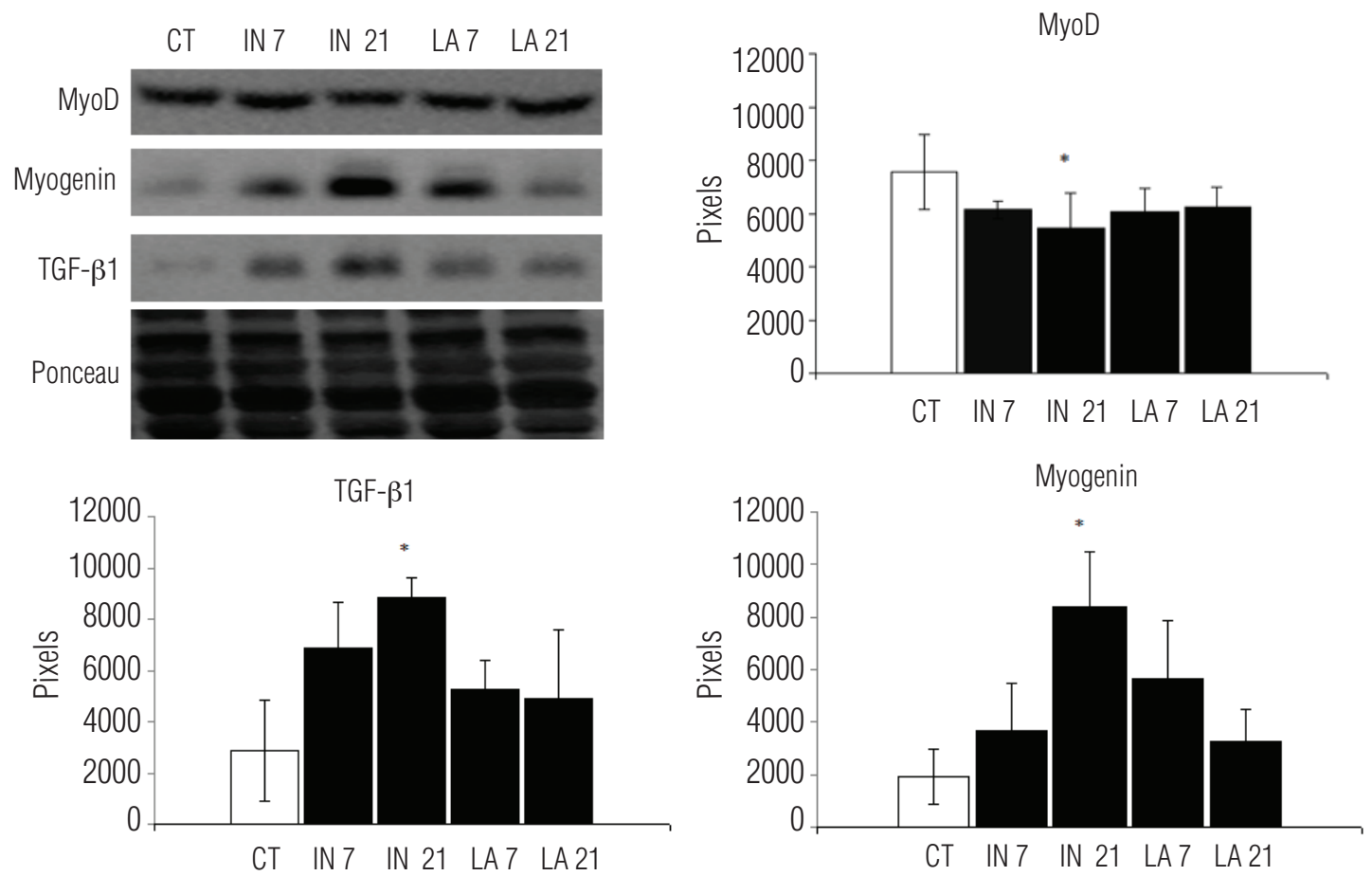

${ }^{*} \mathrm{p}<0.05$ compared to the CT group

Figure 3. Figure of protein bands and sequencing of blotted (Ponceau). Content of MyoD, Miogenin and TGF- $\beta 1$ in the control (CT), injury 7 (IN 7 ), injury 21 (IN 21), laser 7 (LA 7) and laser 21 (LA 21) groups. (Mean \pm SD).

muscle regeneration in the IN 21 group, since the LA 21 group exhibited reduced Myogenin content, probably for having gone through the cell differentiation phase, contrary to the IN 21 group, which was still in this phase. However, it is not possible to affirm the effectiveness of the proposed treatment, since there was no difference between the treated and injury groups (Figure 3).

Given the predisposition of the aged cellular environment towards the formation of fibrosis during the muscle regeneration process, it was considered important to verify the content of a cytokine involved in the formation of collagen, TGF- $\beta 1$. The IN 21 group had significantly higher TGF- $\beta 1$ content compared to the CT group. Despite the LA group having been similar to the CT group, it is not possible to affirm the influence of the laser in preventing fibrosis formation, since there was no difference between the treated and injury groups (Figure 3).

\section{Discussion $\because \therefore$.}

According to what was previously hypothesized, treatment with GaAlAs laser, applied at energy density of $4 \mathrm{~J} / \mathrm{cm}^{2}$, reduced the injury inflammatory process after 21 treatment sessions on an aged experimental model.
The contusion injury chosen for this research is similar to injuries resulting from compressive force traumas that occur in everyday life, principally during sporting activity, thereby being of extreme clinical relevance ${ }^{19}$. The TA muscle was chosen to receive the contusion because of its superficial location, facilitating access to the injury.

In studying muscle regeneration in aged animals, one must consider the installation of the aging process and the effect that it triggers in regeneration. The decline in the quantity of quiescent satellite cells in the skeletal muscle, added to the set of factors that hinder its activation and proliferation, results in a compromise of the function of these cells and consequently a deficiency of the skeletal muscle regenerative capacity in elderly individuals ${ }^{20,21}$.

The change in the myogenic potential of the satellite cells found in this study was also noted by Beccafico et al. ${ }^{22}$. In the muscle cell cultures of young people (average age of 30) and the elderly (average age of 83). After seven days of in vitro cell differentiation, the quantity of satellite cells was not significantly different between the groups, despite being reduced in the aged. However, the melt index analysis (MI), established as the potential of mononucleated myoblasts to merge into multinucleated myotubules, indicated that the MI was significantly reduced in the muscle cells of the aged compared with young people. These results suggest that the deficit in 
muscle regenerative capacity, due to aging, does not simply occur through a reduction in the amount of quiescent satellite cells but probably from a problem during the differentiation phase.

Characteristics of key markers of the muscle regeneration process were studied by van der Poel et al. ${ }^{23}$ and compared among young, adult and aged animals. The analyzes performed within 12, 24, 36, 48 and 72 hours after injury verified that the basal levels of inflammatory cytokines (TNF $\alpha$, IL-6, IL-1 $\beta$, IFN- $\gamma$, CD18 and IL-18) were elevated in the aged when compared with young and adult animals and these cytokines remained elevated in the aged even 72 hours after injury. Although this study did not quantify inflammatory cytokines, this disruption, arising from aging, can also be observed by means of morphometry, since the IN 21 group exhibited intense inflammatory infiltrate even a long time after injury.

Studies involving muscle regeneration in young animals may help us understand the prolonged inflammatory phase due to aging. Winkler et al. ${ }^{24}$ inflicted an injury to the soleus muscle of young animals and noted that, four weeks after the injury, there was no local inflammation, merely dense fibrous tissue in development, contrary to what was observed in this study.

The muscle regeneration process triggers the activation of satellite cells, and, with them, specific markers are expressed in each healing phase that they go through. The initial cell activation and proliferation phase is characterized by the MyoD expression, which increases 3 hours after injury, reaches its peak at 12 hours and subsequently returns to normal ${ }^{25,26}$. In this study, samples were collected after 7 and 21 treatment sessions, which explains why the MyoD content is similar or even reduced in the experimental groups compared to the CT group.

With the advance of regeneration, Myogenin, a particular marker of the satellite cell differentiation phase for the repair or formation of new myoblasts, is expressed. In young animals, its content shows an increase around the third day after injury, reaching its peak on the seventh day, and returning to normal soon after ${ }^{25,26}$. In contrast, these data were not similar to the findings of this study, since the Myogenin content of the IN 21 group exhibited a significant increase when compared to the CT group, even four weeks after the muscle injury. This fact may have attributed to the delay in cell differentiation process by virtue of aging in the experimental model used.

The group that received treatment, despite having Myogenin content similar to the $\mathrm{CT}$ group, did not differ from the IN group. Therefore, given the parameters used, it is not possible to affirm the benefits of the laser in promoting muscle regeneration in aged animals.
The same myogenic markers were observed by van der Poel et al. ${ }^{23}$, in which MyoD expression in young and adult animals showed a significant increase 72 hours after injury while, in the same period, this increase was not seen in aged animals. With regard to Myogenin, a significant increase in MyoD expression was not detectable in aged animals seven days after injury; however, in the same period, there was a $90 \%$ increase in young and adult animals.

TGF- $\beta 1$ is a cytokine expressed during the formation of collagen fibers, therefore it is commonly used to investigate the formation of fibrosis. However, this cytokine also has an influence on the state of satellite cell quiescence, as verified by Rathbone et al. ${ }^{27}$. The addition of TGF- $\beta 1$ in the first 48 hours of the satellite cell culture of adult rats provided a reduction in the quantity of MyoD, demonstrating that TGF- $\beta 1$ interferes with cell activation, causing the cells to remain in a state of quiescence. In this sense, the increase in TGF- $\beta 1$ content, observed in the IN 21 group may also have contributed to the delay in the regenerative process.

A $830 \mathrm{~nm}$ GaAlAs diode laser was chosen for this research due to its high wave length, bearing in mind the need for the beam to reach the muscle, as this is the property that defines laser penetration depth in the irradiated tissue. The energy density established was $4 \mathrm{~J} / \mathrm{cm}^{2}$ per point as indicated for an acute inflammatory process ${ }^{28}$.

As in this work, the effectiveness of laser therapy (633 nm) applied at a low dose was verified by Lyomasa et al. ${ }^{29}$, who used a HeNe laser at $5 \mathrm{~J} / \mathrm{cm}^{2}$ and $10 \mathrm{~J} / \mathrm{cm}^{2}$ on young gerbils after TA muscle injury. After seven consecutive days of treatment, increased mitochondrial activity in muscle fibers, an increase of fibroblasts and macrophages and the stimulation of angiogenesis were noted, suggesting the efficacy of both doses in muscle regeneration. The effectiveness of the laser in reducing the inflammatory process was also seen in this study, however, with the difference that in this study, the effect was delayed and only evident after 21 treatment sessions, which could be attributed to aging.

Rennó et al..$^{30}$ analyzed the regenerative standard of adult animal muscle after the application of $830 \mathrm{~nm}$ laser in the attempt to investigate the action of laser therapy applied at high dosage using a $50 \mathrm{~J} / \mathrm{cm}^{2}$ energy density at a single point. At the end of six treatment sessions, the results of a histological analysis revealed that the laser provided a reduction in the inflammatory response, and the results of immunohistochemistry demonstrated a reduction in COX-2 expression, triggering positive effects in the metabolism of the muscle after injury.

Despite the frequent use of this resource in clinical practice, there is still no standardization in literature in relation to the ideal parameters to be used for muscle regeneration. In this study, we favored the application of daily therapy, using a low 
dosage (energy density of $4 \mathrm{~J} / \mathrm{cm}^{2}$ ), aiming towards the accumulative effects over the treatment period composed of 7 and 21 sessions. However, taking into consideration the findings of other studies and the natural delay in regeneration during aging, it would appear that the parameters used were not sufficient to stimulate tissue effectively. New studies should be conducted using higher energy density and different analysis periods due to the delay in regeneration that occurs with aging.

\section{Conclusion $: \because$.}

Considering the morphological and molecular analyzes performed, as well as the parameters used, it may be concluded that low-level laser therapy affects muscle regeneration of aged animals through its anti-inflammatory effects alone, as the results did not demonstrate an effect on the contents of the proteins studied.

\section{References $: \because$.}

1. Chargé SB, Brack AS, Hughes SM. Aging-related satellite cell differentiation defect occurs prematurely after Ski-induced muscle hypertrophy. Am J Physiol Cell Physiol. 2002;283(4):1228-41.

2. Desaki J. Regeneration of muscle fibers in the extensor digitorum longus muscle of the aged rat. J Electron Microsc (Tokyo). 2008;57(2):59-66.

3. Silva H, Conboy IM. Aging and stem cell renewal. [livro na internet]. Cambridge: Harvard Stem Cell Institute; 2008[acesso 2010 Jun 14]. Disponível em: http://www.stembook.org.

4. Carosio S, Berardinelli MG, Aucello M, Musarò A. Impact of ageing on muscle cell regeneration. Ageing Res Rev. 2011;10(1):35-42.

5. Degens $\mathrm{H}$. The role of systemic inflammation in age-related muscle weakness and wasting. Scand J Med Sci Sports. 2010;20(1):28-38

6. Reddy GK. Photobiological basis and clinical role of low-intensity lasers in biology and medicine. J Clin Laser Med Surg. 2004;22(2):141-50.

7. Shefer G, Partridge TA, Heslop L, Gross JG, Oron U, Halevy 0. Low-energy laser irradiation promotes the survival and cell cycle entry of skeletal muscle satellite cells. J Cell Sci. 2002;115(Pt 7):1461-9.

8. Ortiz MCS, Carrinho PM, Santos AAS, Gonçalves RC, Parizotto NA. Laser de baixa intensidade: princípios e generalidades - Parte 1. Fisioter Bras. 2001;2:221-40.

9. Barbosa AM, Villaverde AB, Guimarães-Souza L, Ribeiro W, Cogo JC, Zamuner SR. Effect of lowlevel laser therapy in the inflammatory response induced by Bothrops jararacussu snake venom. Toxicon. 2008;51(7):1236-44.

10. Lacourt MX, Marini LL. Decréscimo da função muscular decorrente do envelhecimento e a influência na qualidade de vida do idoso: uma revisão de literatura. Revista Brasileira de Ciência do Envelhecimento Humano. 2006;3(1):114-21

11. Oliveira P, Sperandio E, Fernandes KR, Pastor FAC, Nonaka KO, Renno ACM. Comparison of the effects of low-level laser therapy and low-intensity pulsed ultrasound on the process of bone repair in the rat tibia. Rev Bras Fisioter. 2011;15(3):200-5

12. Arruda ERB, Rodrigues NC, Taciro C, Parizotto NA. Influences of different low level laser therapy wavelengths in rat tendon regeneration after tenotomy. Rev Bras Fisioter. 2007;11(4):283-8.

13. Silveira PCL, Silva LA, Tuon T, Freitas TP, Streck EL, Pinho RA. Effects of low-level laser therapy on epidermal oxidative response induced by wound healing. Rev Bras Fisioter. 2009;13(4):281-7.

14. Facio FA, Minamoto VB. Análise morfológia a curto e longo prazo do músculo tibial anterior após contusão. Fisioter Mov. 2006;19(1):73-80.

15. Guirro RRJ, Guirro ECO, Martins CC, Nunes FR. Analysis of low-level laser radiation transmission in occlusive dressings. Photomed Laser Surg. 2010;28(4):459-63.
16. Grounds MD, Torrisi J. Anti-TNFalpha (Remicade) therapy protects dystrophic skeletal muscle from necrosis. FASEB J. 2004;18(6):676-82.

17. Grounds MD, Davies M, Torrisi J, Shavlakadze T, White J, Hodgetts S. Silencing TNF $\alpha$ activity by using Remicade or Enbrel blocks inflammation in whole muscle grafts: an in vivo bioassay to assess the efficacy of anti-cytokine drugs in mice. Cell Tissue Res. 2005;320(3):509-15

18. Marques MJ, Machado RV, Minatel E, Santo Neto H. Disodium cromoglycate protects dystrophin-deficient muscle fibers from leakiness. Muscle Nerve. 2008;37(1):61-7.

19. Järvinen TAH, Järvinen TLN, Kääriäinen $M$, Kalimo H, Järvinen M. Muscle injuries: biology and treatment. Am J Sports Med. 2005;33(5):745-64.

20. Vignaud A, Noirez P, Besse S, Rieu M, Barritault D, Ferry A. Recovery of slow skeletal muscle after injury in the senescent rat. Exp Gerontol. 2003;38(5):529-37.

21. Brack AS, Rando TA. Intrinsic changes and extrinsic influences of myogenic stem cell function during aging. Stem Cell Rev. 2007;3(3):226-37.

22. Beccafico S, Puglielli C, Pietrangelo T, Bellomo R, Fanò G, Fulle S. Age-dependent effects on functional aspects in human satellite cells. Ann N Y Acad Sci. 2007;1100:345-52.

23. van der Poel C, Gosselin LE, Schertzer JD, Ryall JG, Swiderski K, Wondemaghen M, et al. Ageing prolongs inflammatory marker expression in regenerating rat skeletal muscles after injury. J Inflamm (Lond). 2011;8(1):41.

24. Winkler $T$, von Roth $P$, Matziolis G, Schumann MR, Hahn S, Strube P, et al. Time course of skeletal muscle regeneration after severe trauma. Acta Orthop. 2011;82(1):102-11.

25. Srikuea R, Pholpramool C, Kitiyanant Y, Yimlamai T. Satellite cell activity in muscle regeneration after contusion in rats. Clin Exp Pharmacol Physiol. 2010;37(11):1078-86.

26. Corbu A, Scaramozza A, Badiali-DeGiorgi L, Tarantino L, Papa V, Rinaldi R, et al. Satellite cel characterization from aging human muscle. Neurol Res. 2010;32(1):63-72.

27. Rathbone CR, Yamanouchi K, Chen XK, Nevoret-Bell CJ, Rhoads RP, Allen RE. Effects of transforming growth factor-beta (TGF- $\beta 1$ ) on satellite cell activation and survival during oxidative stress. J Muscle Res Cell Motil. 2011;32(2):99-109.

28. Vladimirov YA, Osipov AN, Klebanov Gl. Photobiological principles of therapeutic applications of laser radiation. Biochemistry (Mosc). 2004;69(1):81-90.

29. Iyomasa DM, Garavelo I, Iyomasa MM, Watanabe L, Issa JPM. Ultrastructural analysis of the low level laser therapy effects on the lesioned anterior tibial muscle in the Gerbil. Micron. 2009;40(4):413-8.

30. Rennó ACM, Toma RL, Feitosa SM, Fernandes K, Bossini PS, Oliveira P, et al. Comparative effects of low-intensity pulsed ultrasound and low-level laser therapy on injured skeletal muscle. Photomed Laser Surg. 2011;29(1):5-10. 